\title{
Optical Properties of Berry Epicuticular Waxes in Four Georgian Grape Cultivars (Vitis vinifera L.)
}

\author{
L. Rustioni ${ }^{1 *}$, D. Maghradze ${ }^{2}$, O. Failla ${ }^{1}$ \\ (1) Università degli Studi di Milano, CIRIVE - Centro Interdipartimentale di Ricerca per l'Innovazione in Viticoltura ed \\ Enologia, via Celoria 2, I-20133 Milano, Italy \\ (2) Institute of Horticulture, Viticulture and Oenology, 6 Marshal Gelovani Ave., 0159 Tbilisi, Georgia
}

Submitted for publication: November 2011

Accepted for publication: May 2012

Key words: Epicuticular waxes, reflectance, berry physiology, visible, infrared

\begin{abstract}
The epidermis of plant shoot organs is generally covered by epicuticular waxes. The role of this layer is related mainly to the protection of the inner tissues from biotic and abiotic stresses. In this study, attention is focused on the optical properties of the berry epicuticular waxes of the grapevine (Vitis vinifera $\mathrm{L}$.) at fruit ripening. The reflectance of the berry surface was measured before and after chloroform treatments in four Georgian grape cultivars grown in northern Italy. Epicarp optical properties were underlined at different wavelengths $(341$ to $1025 \mathrm{~nm})$ for each cultivar. The results show that the berry waxes have several optical properties; it is possible that their main eco-physiological effect is to provide specific protection against different types of radiation. Besides the physiological aspects, the results are interesting also from a technical point of view in the field of interpretation of reflectance measurements carried out by non-invasive instruments.
\end{abstract}

\section{INTRODUCTION}

Epicuticular waxes on most plant surfaces (generally fruits and leaves) are deposited as smooth, transparent layers. However, surface waxes on many plants crystallise into structures that look like a coating with a whitish-bluish colour. Plants having this feature are said to be glaucous or to have a wax bloom. When glaucous surfaces are examined using scanning electron microscopy, a myriad of unique epicuticular wax crystals, specific to various species and their organs, are observed (Jenks \& Ashworth, 1999). An observation of the fine structure underlines that the most common structural model of the matrix portion of the cuticle is that of a bilayered cuticular membrane. The outer portion of the cuticle is encrusted with waxes (intracuticular waxes), and a thin film of epicuticular waxes covers the outer surface. In certain species, a more or less dense cover of epicuticular crystals may occur and, because they scatter light, they are responsible for the distinctive visual appearance (Rosenquist \& Morrison, 1988; Müller \& Reiderer, 2005).

In a chemical sense, waxes are esters of long-chain fatty acids with long-chain primary alcohols. In a broad sense, plant epicuticular waxes include a mixture of hydrophobic compounds, with other lipoidal molecules found in the waxes themselves. The structure and chemistry of waxes can differ among plant species, ecotypes of the same species, and organs of the same plants. They can also vary during plant development, and differences have also been observed on different parts of the same leaf (Jenks \& Ashworth, 1999; Müller \& Reiderer, 2005).

The physicochemical characteristics of these surface layers play an important role in plant resistance to a variety of biotic and abiotic stresses, including those caused by fungal and bacterial pathogens, phytophagous insects, drought, freezing temperature, solar radiation, mechanical abrasion, anthropogenic influences, uptake and efficiency of plant growth regulator, and mineral nutrient, pesticide and herbicide sprays (Rosenquist \& Morrison, 1988, 1989; Jenks \& Ashworth, 1999; Müller \& Reiderer, 2005).

It is a common observation that plants growing in environments with high levels of solar radiation often have a thicker layer of epicuticular waxes, which can reflect 20 to $80 \%$ of the incoming radiation, while plants growing in shade conditions reflect about $10 \%$. Even if plant cuticles absorb ultraviolet radiation to varying degrees, the epicuticular waxes of most species do not absorb significant amounts of radiation. However, epicuticular waxes on some species may provide protection by scattering and reflecting incoming radiation. The size, distribution and orientation of the wax crystals, and other surface features, determine the extent to which light is scattered at the tissue surface. Generally, radiation is scattered across the spectrum (in extreme cases it may turn plant surfaces whitish as a result of broadband reflection in the visible part of the solar spectrum), but in some species there is preferential scattering of shorter 
wavelength radiation (Jenks \& Ashworth, 1999; Müller \& Reiderer, 2005). Holmes and Keiller (2002) demonstrated that leaf waxes were very effective reflectors of both UV and longer wavelength radiation. Eucalyptus leaf reflectance was substantially greater at all the wavelengths scanned compared with not-waxy and chloroform-treated leaves. Suffice it to say that the behaviour of succulent plants was different, underlining a specificity of the wax properties (Holmes \& Keiller, 2002).

In fruits, and especially in grapes, research on wax properties is generally focused on the anti-transpirant properties, which are particularly important in post-harvest manipulations for conservation, the drying processes (Mahmutoğlu et al., 1996; Pangavhane et al., 1999; Di Matteo et al., 2000; Doymaz \& Pala, 2002; Doymaz, 2004, 2006; Muganu et al., 2011), and protection against pathogens such as Botrytis cinerea (Marois et al., 1986; Rosenquist \& Morrison, 1988, 1989; Percival et al., 1993).

Rosenquist and Morrison (1988) studied the formation, shape and modification of the epicuticular waxes on Thompson Seedless grapes. They observed that small, individual, upright platelets begin to take shape a few days after anthesis. These rapidly increased in both size and number, reaching the highest density during the lag phase. In the end the platelets spread apart as the berry resumed rapid growth after véraison. In addition to a growth in size, the wax platelets also increased in complexity during berry development, starting as small, simple plates with blunt edges, and finishing as overlapped and lace-like plates, terminating in sharply lobed edges (Rosenquist \& Morrison, 1988).

The aim of this work was to study the optical properties of grape berry epicuticular waxes in different cultivars with various skin colours, measuring the reflectance of the surfaces before and after wax removal by chloroform treatments.

\section{MATERIALS AND METHODS}

In 2011, ripe bunches of four grape varieties (Vitis vinifera L.) were collected in the germplasm collection vineyard of the Regional Research Station of Riccagioia (Lombardy region, northern Italy). The site is located in the Oltrepò pavese viticultural area (long. $9^{\circ} 05^{\prime}$, lat. $44^{\circ} 58^{\prime}$, elevation $144 \mathrm{~m}$ a.s.1.) on a hilly terrace with a slight east exposition with a typical clay soil (Udic Paleustalfs fine silty, mixed, superactive, mesic following the USDA soil taxonomy by Soil Survey Staff, 1999). According to Koeppen's classification (Strahler \& Strahler, 2004), the experimental site has a mesothermal climate with transitional characters between an Oceanic type $(\mathrm{Cfb})$ and a Mediterranean one (Csa). The annual average temperature is $11.7^{\circ} \mathrm{C}$ and the average temperature of January and July is $0.7^{\circ} \mathrm{C}$ and $22.4^{\circ} \mathrm{C}$ respectively. The pluviometric regime presents an annual rainfall varying between 600 and $800 \mathrm{~mm}$, with two maxima (in spring and fall); the winter pluviometric minimum is reflective of the Oceanic type, whereas the summer minimum is indicative of the Mediterranean system.

The vineyard was established in 2006. Plants were spaced at $2.5 \mathrm{~m}$ (inter-row) x $1 \mathrm{~m}$ (intra-row) with a density of 4000 plants/ha, Guyot trained, with a two-bud spur and a 10- to 12-bud cane. The inter-row soil was kept weed free by two yearly glyphosate herbicide treatments.

The plant propagation material was taken from the grapevine collection of Georgian ancient cultivars established in Dighomi (Tbilisi, Georgia) in 1967/1968. Each accession was represented by five plants. The accessions were selected for their colour and for the clear presence of waxes.

Accessions of four Georgian native cultivars, namely Sirgula B., Rkatsiteli Vardisperi Rs., Ghrubela Kartlis G. and Khushia Shavi N., were selected. Beside the interest in the variability of the Georgian grapevine genetic resources, the cultivar selection was made according to the aim of COST Action FA1003, "East-West Collaboration for Grapevine Diversity Exploration and Mobilization of Adaptive Traits for Breeding", within the framework of the "Development of Phenotyping and Genotyping Methodologies" working group.

Ghrubela Kartlis - the name of this variety means 'foggy from the region of Kartli', a feature related to the opaque aspect of the berry due to the abundant wax. Single vines of this variety are spread among the old vineyards of Kartli. The bunch is medium to large in size, conical, seldom cylindrical-conical, winged, medium dense, and sometimes loose. The berry is medium or large in size, ovate, and greygreen to violet. The skin is thin, covered with dense waxes, and easy to peel off. The flesh is juicy and colourless.

Sirgula is a variety from Eastern Georgia. Single vines of Sirgula can be found in the gardens of Kakheti. The bunch is medium in size, cylindrical-conical or cylindrical, winged or sometimes shouldered, medium dense, but seldom very dense. The berry is medium in size, oval or seldom rounded, and light yellow - 'green yellow' according to OIV (2007) descriptor code 225. The skin is difficult to peel off. The flesh is firm and slightly crispy.

Rkatsiteli Vardisperi is a mutant Rkatsiteli grape, selected in the mid-twentieth century. The variety is rarely spread in Kakheti. The bunch is medium in size and large, cylindrical-conical, rarely cylindrical, winged and medium dense. The berry is medium, rounded-ovate and pink. The skin is medium firm. The flesh is colourless, juicy and with a neutral taste.

Khushia Shavi is a black berry variety from the Western part of Georgia. It is a rare wine grape variety from the provinces of Imereti and Guria. It is mainly available in field collections now. The bunch is big, cylindrical or cylindricalconic, winged and medium dense. The berry is medium, rounded or rounded-flattened and black. The flesh is slightly rose and juicy.

All the cultural practices were the same for the four selected cultivars. Spring suckering, post-flowering shoot hedging, topping and positioning, followed by a slight prevéraison leaf removal in the fruiting zone, were the main canopy management steps. Bunch thinning was not required because vine balance, in terms of crop load vs. leaf area ratio, was positively evaluated by visual inspection. It was considered higher than one square metre of exposed leaves per expected kilogram of grapes and able to assure proper grape ripening according to the local experience. Ripeness was evaluated in relation to the varietal characteristics, and some analytical data are reported in Table 1.

For each variety, ten non-deformed and normally sized 
TABLE 1

Grape characterisation at ripe stage.

\begin{tabular}{lcccc}
\hline & Colour & Soluble sugars $\left({ }^{\circ} \mathrm{B}\right)$ & $\mathrm{pH}$ & $\begin{array}{c}\text { Titratable acidity } \\
(\mathrm{g} / \mathrm{L} \text { tartaric acid) }\end{array}$ \\
\hline Rkatsiteli Vardisperi & Pink & 19.7 & 3.0 & 7.8 \\
Ghrubela Kartlis & Grey & 16.9 & 3.2 & 6.9 \\
Khushia Shavi & Black & 18.8 & 2.8 & 13.3 \\
Sirgula & White & 19.4 & 3.2 & 4.3 \\
\hline
\end{tabular}

berries taken from the middle part of representative bunches were selected, and the reflectance was measured in the same area before and after wax removal. All the areas were selected in positions with an evident and uniform wax layer. Chloroform was used to remove the epicuticular waxes (Rosenquist \& Morrison, 1988; Barnes et al., 1996; Holmes \& Keiller, 2002). Berries were rinsed with pure chloroform and wiped with rough paper (to obtain an abrasive effect) three times to ensure the total removal of the waxes.

The measurement of the reflectance was done with the Jaz System (Ocean Optics, B.V.), completed with a spectrometer channel with a DPU module and ILX511b detector, OFLV-3 filter, L2 lens and $50 \mu \mathrm{m}$ slit as installed options. The instrument was set with an NIR/Vis light source intensity of 4095, and an integration time of $100 \mathrm{msec}$. Each spectrum reported by the instrument is shown in arbitrary units (a.u.), and is the average of nine spectra measured and mediated directly by the instrument. The calculated spectra ranged between 341 and $1025 \mathrm{~nm}$, with a stepwise increase of approximately $0.3 \mathrm{~nm}$.

The statistical significance of the differences between the reflectance data from the skins before and after wax removal were estimated for each wavelength according to the classical computation of the mean confidence intervals per $\mathrm{P}=0.95$, with the lower limit at $\mathrm{M}-\left(\mathrm{t}_{0.95}\right)\left(\mathrm{s}_{\mathrm{m}}\right)$ and the upper limit at $\mathrm{M}+\left(\mathrm{t}_{0.95}\right)\left(\mathrm{s}_{\mathrm{m}}\right)$, where $\mathrm{M}=$ average value, $\mathrm{t}=$ Student's t per $\mathrm{P}=0.95$ and $\mathrm{s}_{\mathrm{m}}=$ standard error (standard deviation / number of berries ${ }^{1 / 2}$ ).

\section{RESULTS AND DISCUSSION}

The decision to study original cultivars from Caucasus was linked to the increasing interest in these varieties. Caucasus represents an important centre of genetic variability for Vitis vinifera (Imazio et al., 2010). For this reason it is important to enlarge the research studies on varieties selected in this part of the world. Georgian cultivars in fact show an interesting variability, especially concerning ripening timing (Maghradze et al., 2012). Most of the Georgian cultivars are late ripening and the epicuticular waxes could play an important role in preserving the berry's integrity until the harvest period. This is a further reason to improve existing knowledge of the eco-physiological role of berry epicuticular waxes. For this reason we also selected four Georgian cultivars with berries rich in waxes, even if they are not widely cultivated nowadays.

Figure 1 shows the reflectance spectra of some berries before and after wax removal. Considering that the visual appearance of the skins was clearly modified by the presence of the wax, we were expecting the removal of this layer to cause an evident change in the reflectance spectrum of the berries. Except for the white berry cultivar, however, the differences related to the berries seemed to be higher than the differences related to the presence of epicuticular waxes. Hence, the change in appearance caused by this layer appears to be related mainly to a light-scattering effect, which can be explained by the chaotic orientation of transparent or semi-transparent wax platelets. It may produce an opacification of the berries' surface. However, some changes in the visible spectra were underlined, as shown in Fig. 2. This figure indicates the average spectra and the error for varietal reflectance with and without waxes. A difference in the optical properties of the wax layers was observed among the four varieties, in agreement with the variability of the cultivars' wax structures that have already been underlined (Rosenquist \& Morrison, 1989; Percival et al., 1993; Muganu et al., 2011). Rkatsiteli Vardisperi, the pink cultivar, produced a layer that seemed to increase the reflectance mainly along all the wavelengths of interest in the reflectance phenomenon, but the differences were never significant. In the other three cultivars, the wax presence significantly increased the reflectance in a part of the visible spectrum. The most evident effect appeared in Sirgula, the white variety. In this case, the epicuticular waxes provoked a significant increase in reflectance between about 425 and 655 $\mathrm{nm}$, modifying the optical properties of the surface in nearly all the visible spectra. The increase of reflectance underlined in Ghrubela Kartlis, the grey cultivar, was less pronounced. It involved the visible spectrum approximately between 475 and $620 \mathrm{~nm}$. The high reproducibility of the visible spectra in Sirgula, the black variety, permitted the underlining of a slight but significant increase of the reflectance in the wavelengths included between about 530 and $685 \mathrm{~nm}$.

In Sirgula and Rkatsiteli Vardisperi, the increase in reflectance related to the wax presence seemed to diminish as the wavelength increased. One possible explanation can be related to the nature of the infrared waves. While the UV/ visible waves are able to induce electron transition, the less energetic infrared wavelengths affect vibrational transitions. Therefore, the optical behaviour of the berry in front of the infrared waves will be different in relation to the casual spatial orientation of the molecules. This is in agreement with the results shown in Figure 3, which represent the variability of the optical effects of the wax, showing the confidence intervals of the difference between the reflectance spectrum of the berries covered by waxes and the one obtained after the chloroform treatments. It clearly appears that, in all the varieties, the optical properties of the waxes are much more variable in the less energetic red and infrared wavelengths. 

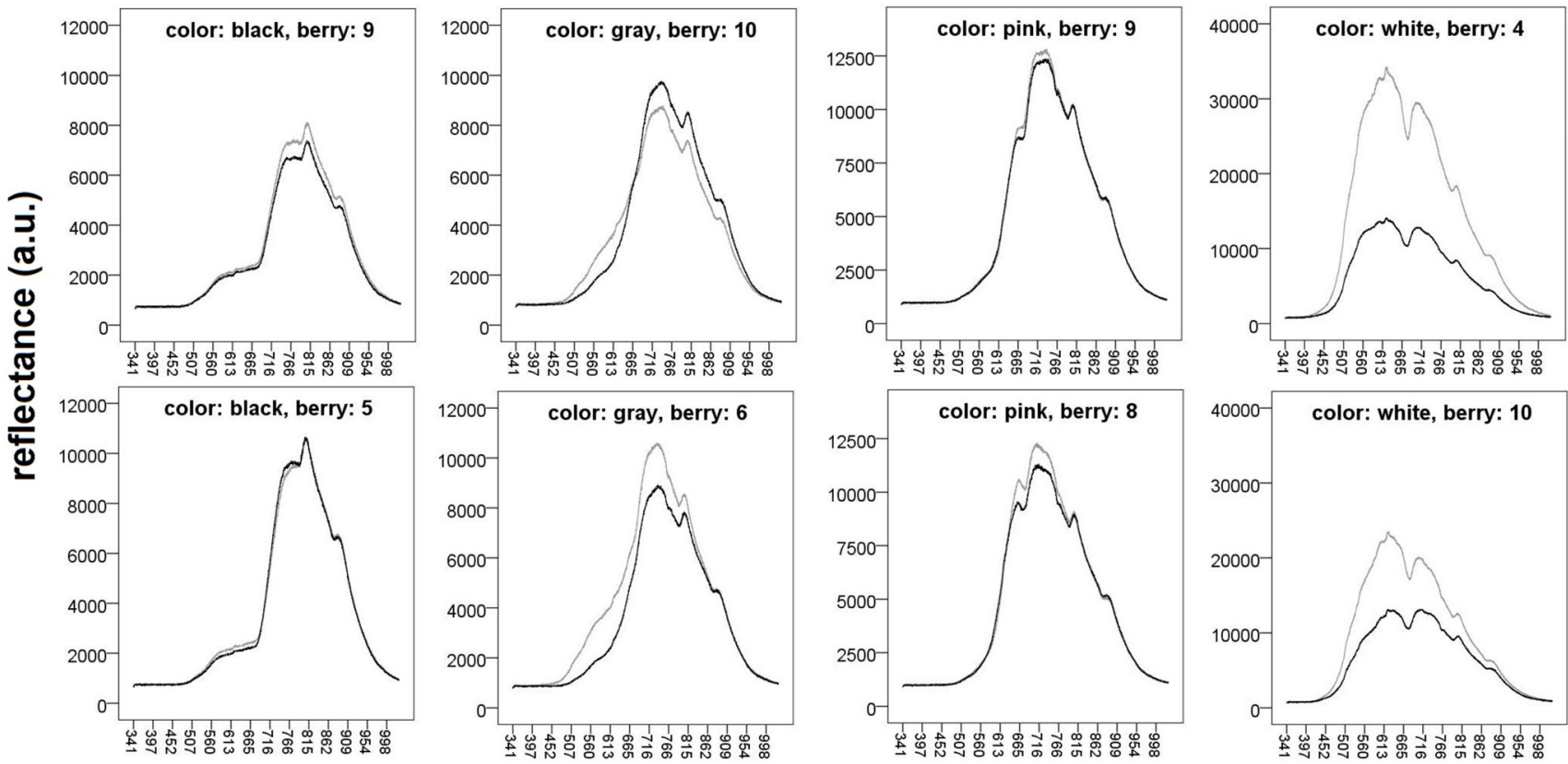

wavelength $(\mathrm{nm})$

FIGURE 1

Example of reflectance spectra with (grey lines) or without (black lines) wax in a single berry. Except for the white cultivar, the differences related to the berries seemed to be higher than the differences related to the presence of epicuticular waxes. Thus, the opacification of the berries' surface observed in the berries covered by waxes should be related mainly to a lightscattering effect. The latter is related to the chaotic orientation of transparent or semi-transparent wax platelets.
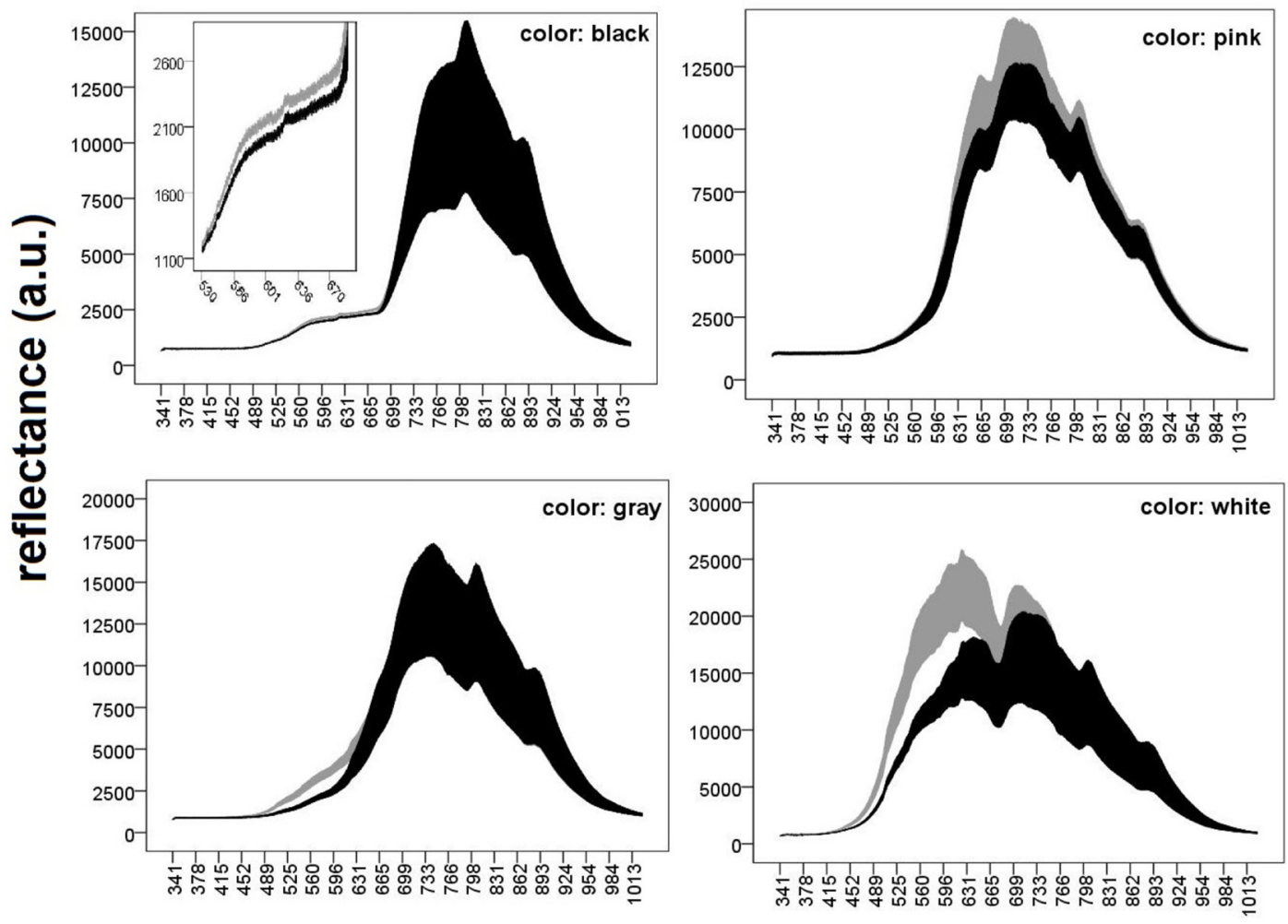

\section{wavelength $(\mathrm{nm})$}

FIGURE 2

Mean confidence intervals (per $\mathrm{P}=0.95$ ) of the reflectance spectra of the four cultivars. The grey areas indicate the reflectance measured in the berries with the wax, while the black areas represent the readings after wax removal. Only Rkatsiteli Vardisperi (pink) did not show a significant increase in reflectance, while in the other varieties the waxes provoked an increase in reflectance in a more-or-less large part of the visible spectra. 


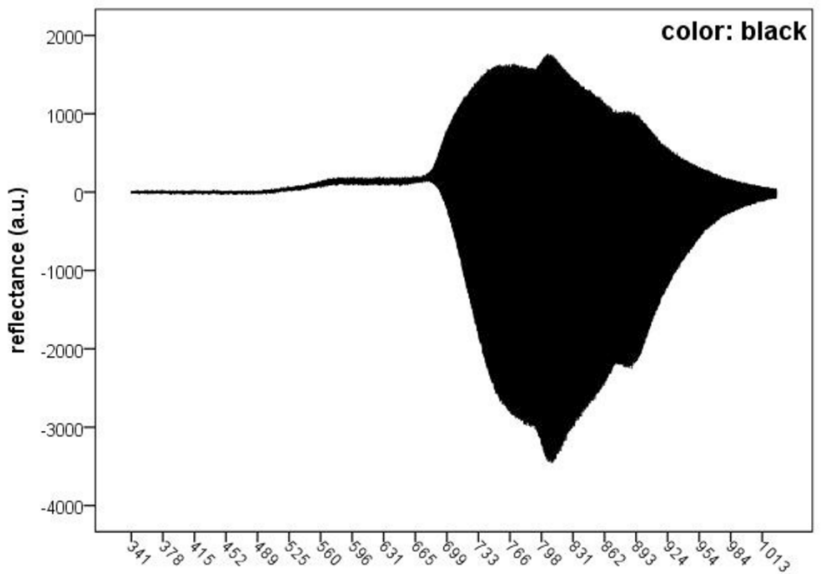

wavelength $(\mathrm{nm})$

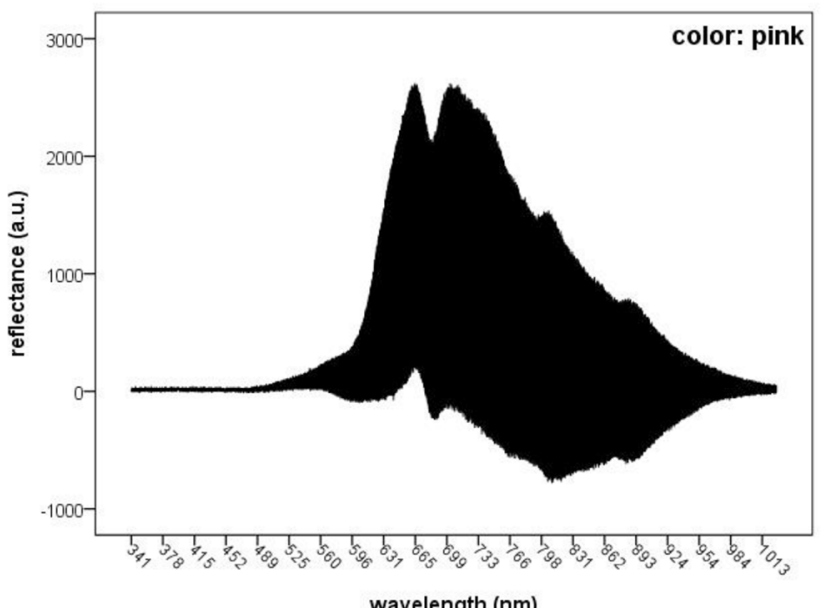

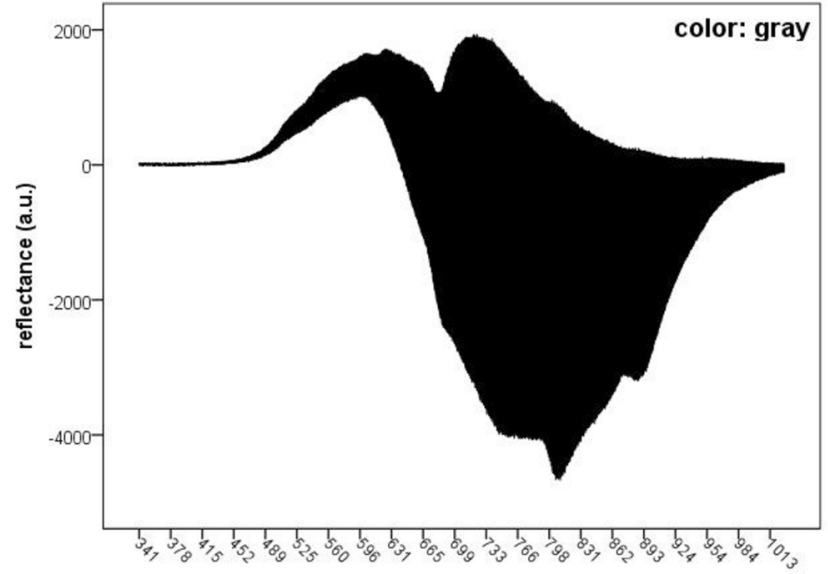

wavelength $(\mathrm{nm})$

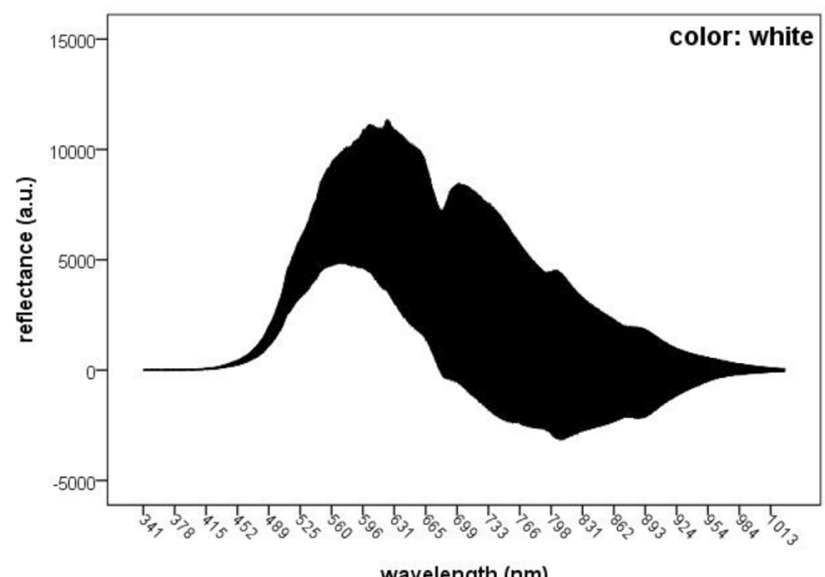

FIGURE 3

Standard errors of the difference between the reflectance spectra before and after the chloroform treatments. This represents the variability of the differences in spectra due to the presence of the wax. The latter generally increases in the IR wavelengths, probably because of the combination of the nature of these waves and the chaotic organisation of the wax platelets.

Considering that the total amount of radiation sent by the instrument to the berry surface can only be transmitted, reflected or adsorbed, the difference between the light measured before and after wax removal may indicate some properties of the waxes, namely:

- principally transmission when this difference is around 0 , because the presence of the wax does not change the amount of light measured;

- mainly reflection when the difference is positive, because the presence of the wax increases the reflectance of the surface;

- some absorption properties when the difference is negative, because the radiation reflected by the rinsed surface would have been stopped by the waxes before arriving back to the instrument.

The high variability of the optical properties of the waxes in the near infrared wavelength region could underline the protective activities of this layer on the basis of different molecular and structural optical properties. The described chaotic disposition of the wax platelets on the berry surface (Marois et al., 1986; Rosenquist \& Morrison, 1988, 1989; Percival et al., 1993; Rogiers et al., 2004; Muganu et al.,
2011) can place molecules in different orientations regarding the flow of radiation. As far as infrared waves are concerned, the chaotic disposition decreases some vibrational transitions depending on the chemical environment, since steric bulk may limit vibrational movements. It thus implies a high variability in the medium optical behaviour, limiting the transmitted radiation. The structural arrangement of the wax was already described as a way to control pathogen infections and water loss. In the crystalline structures, the cuticular transpiration is sharply reduced through this layer because water vapour must be diffused through a complex network of capillaries created by the overlapping platelets. The diffusional dynamics are reduced, making this layer practically impermeable (Hardie et al., 1996; Rogiers et al., 2004). A side effect of the platelets' structure and disposition may have consequences for the optical properties.

\section{CONCLUSION}

Besides for protecting against transpiration and pathogens, the waxes on the grapevine berry proved to have some optical properties, with a eco-physiological side effect. The slight increase in the reflectance in the visible range should 
be taken into account, especially in relation to the cultivar's variability. On the other hand, the overlapping of different optical behaviour in the infrared wavelengths can be related to protection against berry heating.

An improvement in the understanding of the optical properties of the epicuticular waxes of the berry seems important also in the definition of the most suitable cultivars, in particular for warmer viticultural areas. The selection of late ripening cultivars, with berries rich in epicuticular waxes, would allow a reduction in the impact of summer stresses during ripening. At the same time, it would permit better management of an extended ripening phase in the vineyard by reducing possible berry dehydration and mould decay, with a beneficial effect on the oenological quality of the grapes.

Moreover, the results encourage studies in this field in relation to the actual development of non-invasive instruments to evaluate berry ripening and composition. Especially visible and NIR reflectance have recently been used as a new tool in grape research. Knowledge of the optical properties of the epicuticular waxes may help in the development of these methods, where the possible interference of the waxes should be taken into account.

\section{LITERATURE CITED}

Barnes, J.D., Percy, K.E., Paul, N.D., Jones, P., McLaughlin, C.K., Mullineaux, P.M., Creissen, G. \& Wellburn, A.R., 1996. The influence of UV-B radiation on the physicochemical nature of tobacco (Nicotiana tabacum L.) leaf surfaces. J. Exp. Bot. 47, 99-109.

Di Matteo, M., Cinquanta, L., Galiero, G. \& Crescitelli, S., 2000. Effect of a novel physical pretreatment process on the drying kinetics of seedless grapes. J. Food Eng. 46, 83-89.

Doymaz, İ., 2004. Effect of pre-treatments using potassium metabisulphite and alkaline ethyl oleate on the drying kinetics of apricots. Biosyst. Eng. 89, 281-287.

Doymaz, İ., 2006. Drying kinetics of black grapes treated with different solutions. J. Food Eng. 76, 212-217.

Doymaz, İ. \& Pala M., 2002. The effects of dipping pretreatments on airdrying rates of the seedless grapes. J. Food Eng. 52, 413-417.

Hardie, W.J., O’Brien, T.P. \& Jaudzems, V.G., 1996. Morphology, anatomy and development of the pericarp after anthesis in grape, Vitis vinifera L. Aust. J. Grape Wine Res. 2, 97-142.

Holmes, M.G. \& Keiller, D.R., 2002. Effect of pubescence and waxes on the reflectance of leaves in the ultraviolet and photosynthetic wavebands: a comparison of a range of species. Plant Cell Environ. 25, 85-93.
Imazio, S., Maghradze, D., Bacilieri, R., De Lorenzis, G., Scienza, A., This P. \& Failla O., 2010. Molecular survey of Georgian traditional grapevine genetic resources. Book of abstracts, the $10^{\text {th }}$ International Conference on Grape Genetics and Breeding, August 2010, Geneva. p. 70

Jenks, M.A. \& Ashworth, E.N., 1999. Plant epicuticular waxes: function, production, and genetics. Hort. Rev. 23, 1-68.

Maghradze, D., Rustioni, L., Scienza, A. \& Failla O., 2012 Phenological diversity of Georgian grapevine cultivars in northern Italy. J. Amer. Pom. Soc. 66, 56-67.

Mahmutoğlu, T., Emìr, F. \& Saygi, Y.B., 1996. Sun/solar drying of differently treated grapes and storage stability of dried grapes. J. Food Eng. 29, 289-300.

Marois, J.J., Nelson, J.K., Morrison, J.C., Lile, L.S. \& Bledsoe, A.M., 1986. The influence of berry contact within grape clusters on the development of Botrytis cinerea and epicuticular wax. Am. J. Enol. Vitic. 37, 293-296.

Muganu, M., Bellincontro, A., Barnaba, F.E., Paolocci, M., Bignami, C., Gambellini, G. \& Mencarelli, F., 2011. Influence of bunch position in the canopy on berry epicuticular wax during ripening and on weight loss during postharvest dehydration. Am. J. Enol. Vitic. 62, 91-98.

Müller, C. \& Reiderer, M., 2005. Plant surface properties in chemical ecology. J. Chem. Ecol. 31, 2621-2651.

OIV, 2007 (2nd ed). Descriptor list for grape varieties and Vitis species. The OIV, Paris, France.

Pangavhane, D.R., Sawhney, R.L. \& Sarsavadia, P.N., 1999. Effect of various dipping pretreatment on drying kinetics of Thompson seedless grapes. J. Food Eng. 39, 211-216.

Percival, D.C., Sullivan, J.A. \& Fisher, K.H., 1993. Effect of cluster exposure, berry contact and cultivar on cuticular membrane formation and occurrence of bunch rot (Botrytis cinerea Pers.: Fr.) with 3 Vitis vinifera L. cultivars. Vitis $32,87-97$.

Rogiers, S.Y., Hatfield, J.M., Jaudzems, V.G., White R.G. \& Keller M., 2004. Grape berry cv. Shiraz epicuticular wax and transpiration during ripening and preharvest weight loss. Am. J. Enol. Vitic. 55, 121-127.

Rosenquist, J.K. \& Morrison, J.C., 1988. The development of the cuticle and epicuticular wax of the grape berry. Vitis $27,63-70$.

Rosenquist, J.K. \& Morrison, J.C., 1989. Some factors affecting cuticle and wax accumulation on grape berries. Am. J. Enol. Vitic. 40, 241-244.

Soil Survey Staff, 1999 (2nd ed). Soil taxonomy. A basic system of soil classification for making and interpreting soil surveys. USDA - Soil Conservation Service, Agricultural Handbook \#436, U.S. Government Printing Office, Washington, DC.

Strahler, A.H. \& Strahler, A., 2003 (3rd ed). Introducing physical geography. Wiley, New York. 